\title{
Očna duplja, anatomija i neurohirurški pristup (The orbit: Anatomy and neurosurgical approaches)
}

Authors: Ilija Nagulić and Mirjana Nagulić. Publisher: "Obeležja", Belgrade, October 2011, 2 chapters, 202 pages, 46 illustrations and one table.

Danica Grujičić, MD

Professor of neurosurgery, Institute of Neurosurgery

Medical school University in Belgrade, Belgrade, Serbia

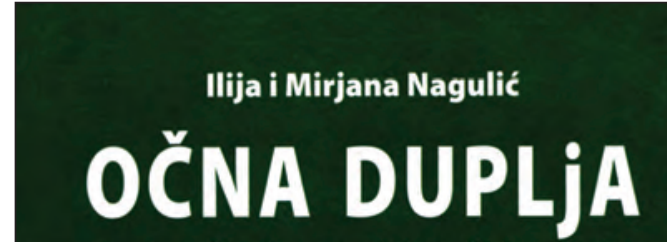
anatomija i neurohirurški pristup

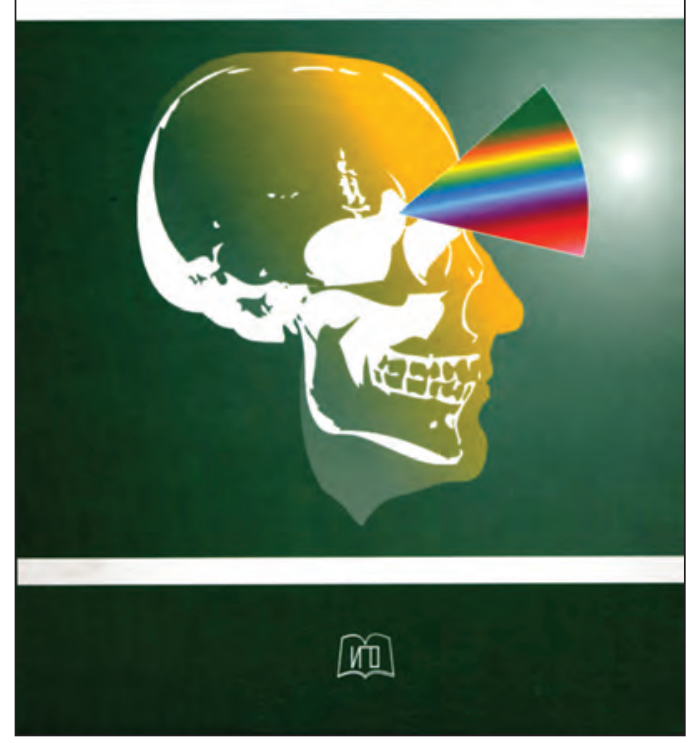

With increasing frequency, the orbit and adjacent areas are being exposed to deal with tumors and other lesions involving the orbit as well as intracranial structures. Difficulties in access to the orbit result from its relatively small volume, irregular quadrilateral pyramid shape and the fact that it is embedded in the craniofacial structures.

It is common for surgeons of different surgical disciplines to come together in the border cranioorbito-facial region. The goal of surgery is always providing the optimum approach that involves the least possible functional and aesthetic damage. The selected approach and techniques have to take into account the nature, location and size of the orbital lesion. Usually, a neurosurgeon is asked to perform surgical procedures for lesions of the orbital apex and which are spreading into neighboring regions of the skull and skull base, making it important to gain an understanding not only of orbital anatomy, but also its relationship to the surrounding areas.

This book has two chapters. The first chapter is devoted to the general anatomy of the orbit with an emphasis on the retrobulbar and structures of the so called "orbito-cavernous junction". Readers are provided with descriptions, applied anatomy for neurosurgical approaches by the well-known international authorities, and by the author's own findings obtained from the cadaveric material. The second section of the first chapter is devoted to a description of microsurgical corridors and frequent anatomical variations of the region. The second chapter deals with neurosurgical approaches to the orbit. The first section of the chapter describes the history of access. Here the authorities and their contribution to the field are given, together with a description of the origin and development of the neurosurgical approach to the orbit in this community. The section on modern surgery describes the most common neurosurgical approaches to the orbit used nowadays, as well as the original approach by dr Ilija Nagulić, described as the "Mini orbitotomy drawer". The text is well illustrated with a number of original photographs and sketches.

Based on the authors' long term surgical experience combined with clinical laboratory research, this book was written to satisfy the interest of all who deal with the problems of orbital diseases, specialists of different branches of medical specializations, and why not, curious medical students. I am pleased to recommend the book "The Orbit. Anatomy and Neurosurgical Approaches". 